Research Paper

\title{
Evaluation of the anatomical parameters for normal tissue sparing in the prone position radiotherapy with small sized left breasts
}

\author{
Hyunjung Kim ${ }^{1,2}$, Jinyoung Kim \\ ${ }^{1}$ Department of Radiation Oncology, Inje University Haeundae Paik Hospital, Busan, Korea \\ ${ }^{2}$ Department of Radiation Oncology, Yonsei University College of Medicine, Seoul, Korea \\ Correspondence to: Jinyoung Kim, email: Jin0416@gmail.com \\ Keywords: breast cancer, prone position, small breast, radiotherapy, heart saving \\ Received: August 24, $2016 \quad$ Accepted: October 07, $2016 \quad$ Published: October 14, 2016
}

\section{ABSTRACT}

Prone position radiotherapy for a small $\left(<750 \mathrm{~cm}^{3}\right)$ breast is controversial because of the variable benefits for the irradiated heart volume. The objective anatomical parameters related with chest wall shape that can determine the heart dose sparing patients in the prone position.

Twenty-one patients underwent CT-simulation in supine and prone position. Dose volume parameters were compared and the objective indexes such as the Haller index, anthropometric index, mid-sternum thickness, and central lung distance (CLD) were evaluated the relationship between the shape of the chest wall and irradiated normal tissue volume in prone position.

The median breast volume was $440.10 \mathrm{~cm}^{3}$ (range, $\left.151.5-727.41 \mathrm{~cm}^{3}\right)$. There was no difference of breast target volume between supine and prone position $(p=0.178)$. The Haller index under $2.5(p=0.046)$, an anthropometric index over $0.05(p=0.007)$, and the CLD over $2(p=0.023)$ conferred a greater heart sparing effect in the prone position.

In conclusions, the objective anatomical parameters related chest wall shape predict the decrease in irradiated heart volume in the prone position. Therefore, it is possible to screen for patients with a reduced heart volume irradiation among those with small breasts before applying prone position radiotherapy.

\section{INTRODUCTION}

In early stage breast cancer, there is no significant difference in survival or local control rate between mastectomy and breast-conserving surgery (BCS) followed by radiotherapy [1-3]. Radiotherapy after BCS generally treats the whole breast using a tangential technique with two fields of radiation beams in the supine position. This method includes the entire breast parenchyma, but it is also irradiates other tissues: the skin, ipsilateral lung, heart, and contralateral breast. Therefore, radiation-induced morbidity can occur $[4,5]$.

There are some options to reduce radiation-induced morbidity. First, intensity modulated radiotherapy (IMRT) techniques using volumetric arc therapy (V-MAT) or static tomotherapy can reduce the radiation dose to other tissues $[6,7]$. Second, respiration control including the deep inhalation breath holding (DIBH) technique can reduce the irradiated heart volume $[8,9]$. Third, the prone position can reduce the radiation dose to the normal tissue volume $[10,11]$. The prone position makes breast tissue unfold away from body tissues because of gravity, and therefore, radiation homogeneity and conformity might be increased [12]. Increased radiation dose homogeneity and conformity leads to a reduction in the radiation dose to tissues such as the lung and heart [13], [14]. Therefore, a patient with large and pendulous breasts has an advantage in the prone position. $[15,16]$

However, prone position radiotherapy for a small or thin breast is controversial. This is because these patients have no advantage from gravity in the prone position because of their small and dense breast parenchymal tissue. It has been reported [17] that shortening the distance between the heart and chest wall because of gravity might increase the irradiated volume of the heart in the prone position. Radiation dose homogeneity and conformity worsens as the breast parenchymal volume decreases [18]. There are few studies of prone position radiotherapy in patients with small breasts. But most of Asian women and leaner body shaped women had a small sized breast. 
In this study, we hypothesized that there is a relationship between irradiated normal tissue volume and the chest wall shape rather than the breast shape and volume. We analyzed several objective anatomical parameters that might be able to predict the value of sparing other tissues in patients with small sized breasts in the prone position during radiation therapy.

\section{RESULTS}

\section{Patients and treatment characteristics}

There were 21 enrolled women with a mean age of 54 (range, 38-80). All patients had left breast cancer with a breast volume of less than $750 \mathrm{~cm}^{3}$. Three cases were stage 0 and 18 were stage IA. Moreover, patients had ductal carcinoma $(n=2)$, lobular carcinoma in situ $(n=1)$, and invasive ductal carcinoma $(n=12)$, invasive lobular carcinoma $(n=2)$, mucinous carcinoma $(n=2)$, and tubular carcinoma $(n=2)$. Their body mass index (BMI) was median 23.43 (range, 19.28-30.23).

The patients' anatomical parameters in supine position are summarized in Table 1. The median breast volume was $440.10 \mathrm{~cm}^{3}$ (range, 151.5-727.41) in the prone position, and the breast volumes were not significantly different when compared to in the supine position $(p=0.178)$. The patients were divided into groups based on breast volume $<350 \mathrm{~cm}^{3}, 351-550 \mathrm{~cm}^{3}, 551-750 \mathrm{~cm}^{3}$, and there were 7,6 , and 8 per group, respectively. The median Haller index was 2.63 (range, 1.86-3.37), the median anthropometric index was 0.05 (range, 0.002-0.1), and the median midsternum thickness was 1.69 (range, 0.79-2.47). The median central lung distance (CLD) for radiation treatment plans in the supine position was 2.37 (range, 1.28-3.17).

\section{Planning values}

Table 2 shows the dosimetric endpoints of radiation in the supine and prone position. Whereas conformity number $(\mathrm{CN})$ has statistically different according to position $(p<0.0001)$, there was no difference in terms of homogeneity index (HI) $(p=0.079)$. The lung volume was approximately $11 \%$ higher when measured in the prone position than in the supine position $(p<0.0001)$. In the supine position, the irradiated ipsilateral lung volume was $136 \mathrm{~cm}^{3}$, compared to $17.02 \mathrm{~cm}^{3}$ in the prone position $(p<$ $0.0001)$. The V20 ( $p=0.001), \mathrm{V} 5(p=0.001)$, and $\mathrm{D}_{\text {mean }}(p$ $=0.001$ ) for the heart were significantly different. However, the left anterior descending coronary artery (LAD) demonstrated no significant differences in V40 $(p=0.148)$, $\mathrm{V} 5(p=0.870), \mathrm{D}_{\text {mean }}(p=0.372)$, or $\mathrm{D}_{\text {max }}(p=0.663)$.

\section{Effects of anatomical variables}

Table 3 shows that the mean differences of irradiated lung, heart and LAD volumes classified by anatomical variables. The patients were divided into three groups by breast volume: $<350 \mathrm{~cm}^{3}, 351-550 \mathrm{~cm}^{3}$, and $551-750 \mathrm{~cm}^{3}$. The differences in irradiated lung volume between the supine and prone position for these three groups were $141.85 \mathrm{~cm}^{3}, 126.27 \mathrm{~cm}^{3}$, and $96.72 \mathrm{~cm}^{3}$, respectively. In fact, the CLD value greater than 2 obtained after the radiation treatment plan that was established in the supine position shows that larger lung volume values can be spared in the prone position.

The irradiated heart volume was different in the supine position compared with the prone position when the breast volume was $551-750 \mathrm{~cm}^{3}(p=0.008)$. The thick mid sternum group $(p=0.009)$ can more heart sparing in the prone position. When the BMI was $<23.4$, there was a significant difference between the prone and supine groups $(p=0.005)$. The Haller index showed a significant difference in terms of heart sparing when greater than 2.5 in prone position. An anthropometric index over 0.05 had a greater heart sparing effect in the prone position than in the supine position. A large CLD resulted in a greater heart sparing effect in the prone position. However, for LAD, there was no difference based on the chest wall shape indexes.

\section{DISCUSSION AND CONCLUSIONS}

Prone positioned radiotherapy has a benefit in terms of irradiated lung volume in all cases, but the prone position for small breasts is not actively used because of the variable irradiated heart and LAD volume [17], [19]. In this study, prone position radiotherapy minimized the irradiated lung volume, but there was no advantage for the LAD. Compared with the supine position, the distance between the left ventricle and anterior rib is shortened by gravity [12].

Formenti et al. [19] showed that they divided into groups based on breast volume $<750,751-1500$, $>1500 \mathrm{~cm}^{3}$. They insisted that there was a patient with large breasts (over $750 \mathrm{~cm}^{3}$ ) has an advantage in the prone position. But prone position for a small (under $750 \mathrm{~cm}^{3}$ ) or thin breast is controversial. But most of Asian women and leaner body shaped women had a small sized breast. Even $550-750 \mathrm{~cm}^{3}$ sized breast consider large breast volume in Asian patients. Therefore we divided into groups based on breast volume $<350,351-750,>750 \mathrm{~cm}^{3}$.

Chen et al. [7] reported that there were no significant differences between the prone and supine position for irradiated heart volume based on a breast volume of 450 $\mathrm{cm}^{3}$. On the contrary, our study showed that a decreasing irradiated heart volume was obtained in the prone position for the largest breast volume group $\left(551-750 \mathrm{~cm}^{3}\right)$. Our results demonstrate that even though the breast volume is small, the benefit to the irradiated heart volume depends on how the volumetric criteria are applied. Varga et al. $[20,21]$ reported that patients with a BMI greater than 26.3 benefit from heart protection in the prone position. In this study, however, the patients' median BMI was 23.43 (range, 19.28-30.23), lower than that of the patients in 
$N=21$

Breast volume $\left(\mathrm{cm}^{3}\right)$ in prone

Median

Range

(151.5-727.41)

$\leq 350$

7

$351-550$

6

551-750

8

BMI $\left(\mathrm{kg} / \mathrm{m}^{2}\right)$

Median

Range

Haller index

Median

Range

Anthropometric index

Median

Range

Mid sternum thickness (cm)

Median

Range

CLD $(\mathrm{cm})$

Median

Range

CLD, central lung distance.

Varga's study. Heart protective effects were also observed in our study in patients with a BMI less than 23.43. Because of ethnic differences, BMI-based results might be different between Asians and western populations. However, breast volume and BMI are quantitative numerical values; therefore, it is difficult to predict the benefits of irradiated heart volume in the prone position.

In this study, we applied various anatomical indexes to objectively predict the decrease in irradiated heart volume in the prone position. We found that the reduced irradiated heart volume was significantly larger in the group with a Haller index less than $2.5(p=0.0046)$, the group with an anthropometric index over $0.05(p=0.007)$, and the group with a CLD over $2(p=0.023)$. Because these indexes reflect the chest wall shape, it possible that these three indexes might be able to predict the heart sparing benefits in certain conditions.

The smaller the heart dose and volume patients receive, the lower the incidence of cardiovascular disease [20]. If the chest wall shape of patients is expressed by an objective numerical value, it is possible to screen for patients with a reduced heart volume irradiation among those with small breasts before applying prone position radiotherapy. Accordingly, before generating treatment plans, it will be possible to consider prone position radiotherapy. However, this study is not free from selection bias because of the small number of patients and the fact that it is a single institution study.

In conclusion, the irradiated heart volume depends on the chest wall shape in women with small breasts. It is possible to predict the reduced irradiated heart volumes in these patients with objective indexes.

\section{MATERIALS AND METHODS}

This study has been approved by the Haeundae Paik Hospital Institutional Review Board.

\section{Patient positioning and image acquisition}

From May to June 2015, 21 early stage left breast cancer patients who underwent BCS and received radiotherapy were enrolled. Simulation computed tomography (CT) images (Somatom Sensation Open, 


\begin{tabular}{|c|c|c|c|c|c|}
\hline & \multirow[t]{2}{*}{ prone setup } & \multicolumn{3}{|c|}{ supine setup } & \multirow[t]{2}{*}{$p$-value } \\
\hline & & (SD) & & (SD) & \\
\hline \multicolumn{6}{|l|}{ Breast } \\
\hline Volume $\left(\mathrm{cm}^{3}\right)$ & 440.10 & 155.93 & 445.04 & 156.03 & 0.178 \\
\hline $\mathrm{HI}$ & 1.12 & 0.03 & 1.10 & 0.03 & 0.079 \\
\hline $\mathrm{CN}$ & 0.76 & 0.06 & 0.71 & 0.53 & 0.000 \\
\hline V105 (\%) & 1.07 & 1.50 & 1.34 & 1.33 & 0.478 \\
\hline V107 (\%) & 0.00 & 0.00 & 0.00 & 0.00 & \\
\hline \multicolumn{6}{|l|}{ Ipsilateral lung } \\
\hline Volume $\left(\mathrm{cm}^{3}\right)$ & 1114.15 & 177.97 & 999.79 & 153.09 & 0.000 \\
\hline V30 (\%) & 1.16 & 1.66 & 12.80 & 2.98 & 0.000 \\
\hline V20 (\%) & 1.48 & 1.85 & 14.11 & 3.04 & 0.000 \\
\hline V10 (\%) & 2.24 & 2.35 & 17.98 & 3.24 & 0.000 \\
\hline V5 (\%) & 3.95 & 3.31 & 25.33 & 3.71 & 0.000 \\
\hline $\mathrm{D}_{\text {mean }}(\mathrm{Gy})$ & 1.46 & 0.98 & 7.92 & 1.42 & 0.000 \\
\hline $\mathrm{D}_{\max }(\mathrm{Gy})$ & 42.31 & 12.19 & 50.30 & 0.76 & 0.000 \\
\hline In-field lung volume & 14.28 & 17.02 & 136.55 & 42.33 & 0.000 \\
\hline \multicolumn{6}{|l|}{ Heart } \\
\hline V20 (\%) & 3.44 & 2.54 & 6.28 & 3.39 & 0.001 \\
\hline V5 (\%) & 7.35 & 3.67 & 10.65 & 4.45 & 0.001 \\
\hline $\mathrm{D}_{\text {mean }}(\mathrm{Gy})$ & 2.76 & 1.22 & 4.14 & 1.64 & 0.001 \\
\hline $\mathrm{D}_{\max }(\mathrm{Gy})$ & 49.21 & 2.22 & 50.04 & 3.56 & 0.370 \\
\hline \multicolumn{6}{|l|}{$\mathrm{LAD}$} \\
\hline V40 (\%) & 16.93 & 13.92 & 22.62 & 15.42 & 0.148 \\
\hline V5 (\%) & 42.48 & 16.19 & 43.16 & 13.04 & 0.870 \\
\hline $\mathrm{D}_{\text {mean }}(\mathrm{Gy})$ & 13.47 & 6.88 & 15.08 & 6.71 & 0.372 \\
\hline $\mathrm{D}_{\max }(\mathrm{Gy})$ & 42.68 & 10.78 & 43.89 & 10.41 & 0.663 \\
\hline
\end{tabular}

SD, standard deviation; HI, Homogeneity index; CN, Conformity number; LAD, left anterior descending coronary artery.

Siemens, Forchheim, Germany) were taken with a thickness of $3 \mathrm{~mm}$ with no contrast. The scanning range was from the first cervical to the 12th thoracic spine level. All of the patients had their palpable breast tissue marked by a radio-opaque wire in the supine position. They were re-scanned again in the prone position using a prone breast support (kVue ${ }^{\mathrm{TM}}$ Access $360^{\mathrm{TM}}$, Qfix, Avondale, USA). The position of the knees, arms, and the orientation of nipples and faces were thoroughly recorded. CT scans for the prone position were performed the same as in the supine position.

\section{Target and non-target tissue delineation}

The clinical target volume (CTV) included all visible or palpable breast tissue on simulation $\mathrm{CT}$, followed by the usual guideline to be set from the skin under $5 \mathrm{~mm}$ in the supine position [22,23]. Because of the lack of delineation guidelines for the prone position, the usual delineation guidelines for the supine position were used after considering the changes in anatomy in the prone position. The CTV was delineated by including all visible breast parenchymal tissue, laterally the lateral thoracic artery, medially the lateral position of the sternum, cranially a $2-\mathrm{cm}$ margin from the breast parenchymal tissue, caudally the breast fold, ventrally a $5-\mathrm{mm}$ margin from the skin, and dorsally above the intercostal muscle. The LAD was inferentially delineated from the course of the anterior-interventricular groove. Ipsilateral-lung, contralateral breast and heart, and humeral head were outlined. 
Table 3: Subgroup analysis of mean differences in the irradiated lung, heart, and left anterior descending coronary artery in the supine and the prone position

\begin{tabular}{|c|c|c|c|c|c|c|c|c|c|c|c|c|c|c|c|c|}
\hline & \multicolumn{6}{|c|}{$\begin{array}{l}\text { In-field Lung Volume, } \\
\quad \text { Mean }\left( \pm \text { SD) } \mathrm{cm}^{3}\right.\end{array}$} & \multicolumn{4}{|c|}{$\begin{array}{l}\text { In-field Heart Volume, } \\
\quad \text { Mean }( \pm \text { SD }), \mathrm{cm}^{3}\end{array}$} & \multicolumn{6}{|c|}{$\begin{array}{l}\text { In-field LAD Volume } \\
\text { Mean }( \pm \text { SD }), \mathbf{c m}^{3}\end{array}$} \\
\hline & No. & supine & (SD) & prone & (SD) & $p$-value & supine & (SD) & prone & (SD) & $p$-value & supine & (SD) & prone & (SD) & $p$-value \\
\hline \multicolumn{17}{|c|}{ Breast volume $\left(\mathrm{cm}^{3}\right)$} \\
\hline$\leq 350$ & 7 & 167.22 & 37.62 & 25.37 & 21.56 & 0.001 & 10.15 & 3.00 & 8.40 & 2.64 & 0.122 & 44.62 & 7.34 & 41.72 & 12.06 & 0.516 \\
\hline $351-550$ & 6 & 140.86 & 35.06 & 14.59 & 15.27 & 0.000 & 10.23 & 4.86 & 7.60 & 4.68 & 0.145 & 39.40 & 16.15 & 43.91 & 21.98 & 0.577 \\
\hline $551-750$ & 8 & 99.43 & 31.12 & 2.72 & 1.48 & 0.001 & 11.77 & 5.51 & 5.92 & 2.80 & 0.008 & 47.33 & 12.63 & 41.08 & 11.09 & 0.460 \\
\hline \multicolumn{17}{|c|}{ BMI (kg/m2) } \\
\hline$<23.4$ & 11 & 150.72 & 47.04 & 19.35 & 18.34 & 0.000 & 9.78 & 3.10 & 6.56 & 3.20 & 0.005 & 44.83 & 12.85 & 38.15 & 13.05 & 0.052 \\
\hline$\geq 23.4$ & 10 & 120.97 & 31.74 & 8.69 & 14.29 & 0.000 & 11.60 & 5.60 & 8.21 & 4.11 & 0.070 & 41.32 & 13.67 & 47.24 & 18.57 & 0.460 \\
\hline \multicolumn{17}{|c|}{ Mid sternum thickness $(\mathrm{cm})$} \\
\hline$<1.6$ & 8 & 150.40 & 49.88 & 19.41 & 19.13 & 0.000 & 9.09 & 2.70 & 7.14 & 3.80 & 0.039 & 36.23 & 10.82 & 40.04 & 16.48 & 0.496 \\
\hline$\geq 1.6$ & 13 & 128.03 & 36.44 & 11.12 & 15.53 & 0.000 & 11.61 & 5.11 & 7.48 & 3.73 & 0.009 & 47.42 & 12.77 & 43.98 & 16.49 & 0.565 \\
\hline \multicolumn{17}{|c|}{ Haller index } \\
\hline$\leq 2.5$ & 6 & 143.45 & 43.49 & 11.32 & 12.66 & 0.001 & 14.97 & 3.83 & 9.43 & 2.74 & 0.046 & 50.57 & 14.29 & 55.95 & 12.17 & 0.540 \\
\hline$>2.5$ & 15 & 133.79 & 43.07 & 15.46 & 18.75 & 0.000 & 8.92 & 3.44 & 6.51 & 3.73 & 0.527 & 40.19 & 11.70 & 37.09 & 14.58 & 0.527 \\
\hline \multicolumn{17}{|c|}{ Anthropometric index } \\
\hline$<0.05$ & 9 & 117.09 & 39.44 & 12.63 & 12.04 & 0.000 & 8.54 & 3.94 & 6.72 & 3.34 & 0.092 & 40.76 & 12.12 & 41.51 & 17.06 & 0.932 \\
\hline$\geq 0.05$ & 12 & 151.15 & 39.80 & 15.51 & 20.43 & 0.000 & 12.23 & 4.28 & 7.82 & 3.97 & 0.007 & 44.96 & 13.92 & 43.20 & 16.23 & 0.645 \\
\hline \multicolumn{17}{|l|}{ CLD (cm) } \\
\hline$<2$ & 4 & 97.20 & 26.24 & 8.13 & 13.93 & 0.002 & 8.60 & 5.10 & 5.15 & 0.79 & 0.307 & 47.30 & 16.58 & 42.00 & 19.23 & 0.775 \\
\hline $2-2.49$ & 7 & 128.91 & 33.65 & 19.71 & 21.83 & 0.000 & 9.30 & 3.73 & 7.24 & 3.34 & 0.023 & 39.16 & 10.44 & 37.09 & 13.54 & 0.772 \\
\hline$\geq 2.5$ & 10 & 157.64 & 42.06 & 12.93 & 14.82 & 0.000 & 12.41 & 4.40 & 8.30 & 4.37 & 0.023 & 44.30 & 13.85 & 46.44 & 17.23 & 0.617 \\
\hline
\end{tabular}

$S D$, standard deviation; $L A D$, left anterior descending artery, BMI, body mass index; CLD, central lung distance.

\section{Anatomical parameters}

The following four indexes were used to measure the chest wall shape in supine position (Table 1)

1) Haller index [24] (Figure 1A): A CT tomographic measurement for the ratio of the greatest latero-lateral distance (A-Haller) and the shortest sterno-posterior distance (C-Haller) $($ Haller index $=$ A-Haller/C-Haller). This is an index to evaluate the chest wall deformity of the pectus excavatum, using 2.5 as a normal reference. An index greater than 2.5 indicates that the chest wall is concave.

2) Anthropometric index (Figure 1B): The ratio of the largest anteroposterior diameter (A-clinical) in the distal third area of the sternum level and the largest depth during a deep inhalation (B-clinical) of the same level (anthropometric index = B-clinical/A-clinical). It is a cosmetic indicator used in orthopedics to describe the chest wall shape when viewed from the outside.
For women, the chest wall shape is covered with breast parenchyma tissue, and by using the anthropometric index, it is possible to know both the shape of the entire chest wall and breast.

3) Midsternum thickness (Figure 1C): The thickness of the midsternal area at the nipple level in the supine position.

4) CLD (Figure 1D): When planned in the supine position, it is the lung distance in the projection of the tangential fields at the level of the central axis. CLD presents the chest wall concavity in the supine position.

\section{Dose prescription and radiotherapy planning}

We prescribed 50.4 Gy in 28 fractions over 6 weeks (6-15 MV photons) to the $95 \%$ isodose. For each position, standard opposed tangential-fields were employed. Plans were generated on the basis of the International 
Commission on Radiation Units and Measures (ICRU) dose-homogeneity criteria. They were reviewed with dose distributions and dose-volume-histograms (DVHs). A radiation treatment planning system (Eclipse 11, Varian Medical Systems, Palo Alto, USA) was utilized. The field-in-field (FIF) technique, including of two main fields and four to six subfields, was used to increase dose homogeneity (Figure 2). All of the added subfields were merged into two tangential radiation fields. Moreover, collimator angles were adjusted to the CTV shapes, and asymmetric jaws were optimized to reduce the radiation dose to the lungs. For the radiation dose calculations, a 2.5-mm grid size and an anisotropic analytical algorithm was applied to all plans.

\section{Planning evaluation}

Several dosimetrical parameters such as CN, HI, radiation dose received, and maximum and mean doses were used. The following were used: $\mathrm{CN}$ [18]: $\mathrm{TV}_{\mathrm{RI}} / \mathrm{TV}$ $\times \mathrm{TV}_{\mathrm{RI}} / \mathrm{V}_{\mathrm{RI}}\left(\mathrm{TV}=\right.$ target volume, $\mathrm{TV}_{\mathrm{RI}}=$ target volume covered by the reference dose, $\mathrm{V}_{\mathrm{RI}}=$ volume of the reference dose); HI [25]: $\mathrm{D}_{5 \%} / \mathrm{D}_{95 \%}\left(\mathrm{D}_{5 \%}=\right.$ dose received by $5 \%, \mathrm{D}_{95 \%}=$ dose received by $95 \%$ ). CTV coverages were analyzed by using the volume receiving at least 95\% (V95), 105\% (V105), and 107\% (V107) of the prescribed dose. Lung, heart, and LAD were analyzed by maximum dose $\left(\mathrm{D}_{\max }\right)$ and mean dose $\left(\mathrm{D}_{\text {mean }}\right), \mathrm{V} 5, \mathrm{~V} 10$, $\mathrm{V} 20$, and V40.
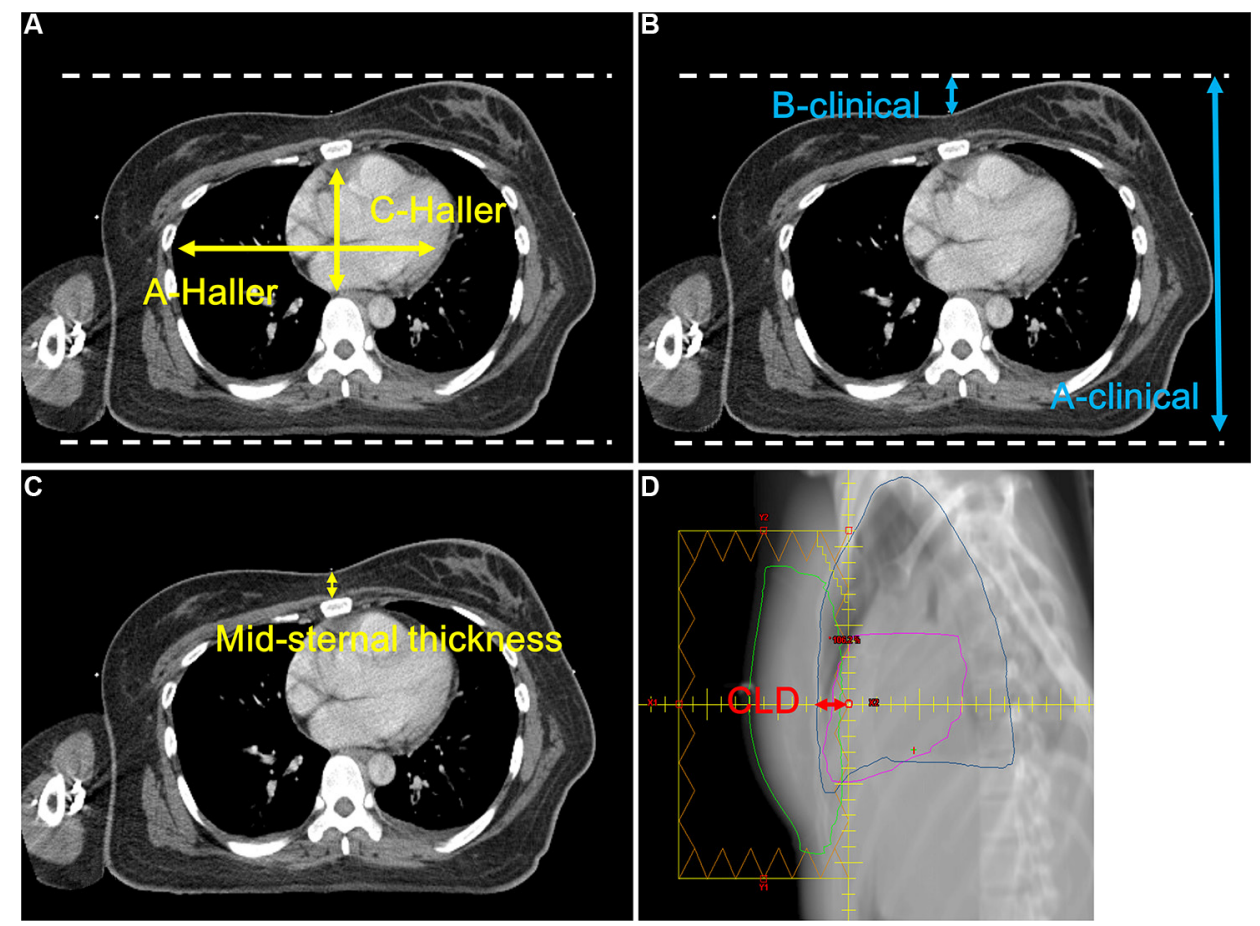

Figure 1: Anatomical parameters. (A) Haller index, (B) anthropometric index, (C) mid sternum thickness, (D) central lung distance.

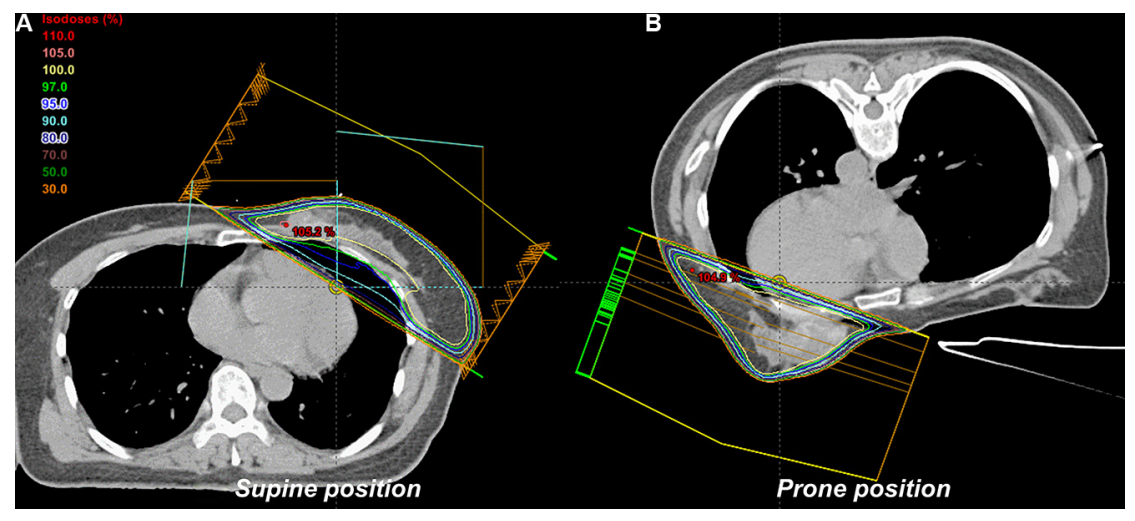

Figure 2: Radiotherapy plan in the (A) supine and (B) prone position. 


\section{Statistical analysis}

Statistical analysis was performed with Student's $t$-test, defining a $p$ value $<0.05$ as statistically significant. All data were then pooled by breast volume into tertiles $\left(<350,351-550\right.$, and 551-750 $\left.\mathrm{cm}^{3}\right)$, BMI, Haller index, anthropometric index, mid-sternum thickness, and CLD. For both the supine and prone position, the differences in the radiation doses to the lung, heart, and LAD volume were calculated and compared by tertile using the Wilcoxon test.

\section{CONFLICTS OF INTEREST}

No potential conflicts of interest relevant to this article was reported.

\section{REFERENCES}

1. van Dongen JA, Voogd AC, Fentiman IS, Legrand C, Sylvester RJ, Tong D, van der Schueren E, Helle PA, van Zijl K, Bartelink H. Long-term results of a randomized trial comparing breast-conserving therapy with mastectomy: European Organization for Research and Treatment of Cancer 10801 trial. J Natl Cancer Inst. 2000; 92:1143-1150.

2. Fisher B, Anderson S, Bryant J, Margolese RG, Deutsch M, Fisher ER, Jeong JH, Wolmark N. Twenty-year followup of a randomized trial comparing total mastectomy, lumpectomy, and lumpectomy plus irradiation for the treatment of invasive breast cancer. N Engl J Med. 2002; 347:1233-1241.

3. Poggi MM, Danforth DN, Sciuto LC, Smith SL, Steinberg SM, Liewehr DJ, Menard C, Lippman ME, Lichter AS, Altemus RM. Eighteen-year results in the treatment of early breast carcinoma with mastectomy versus breast conservation therapy: the National Cancer Institute Randomized Trial. Cancer. 2003; 98:697-702.

4. Hurkmans CW, Borger JH, Bos LJ, van der Horst A, Pieters BR, Lebesque JV, Mijnheer BJ. Cardiac and lung complication probabilities after breast cancer irradiation. Radiother Oncol. 2000; 55:145-151.

5. Omarini C, Thanopoulou E, Johnston SR. Pneumonitis and pulmonary fibrosis associated with breast cancer treatments. Breast Cancer Res Treat. 2014; 146:245-258.

6. Michalski A, Atyeo J, Cox J, Rinks M, Morgia M, Lamoury G. A dosimetric comparison of 3D-CRT, IMRT, and static tomotherapy with an SIB for large and small breast volumes. Med Dosim. 2014; 39:163-168.

7. Chen JL, Cheng JC, Kuo SH, Chan HM, Huang YS, Chen YH. Prone breast forward intensity-modulated radiotherapy for Asian women with early left breast cancer: factors for cardiac sparing and clinical outcomes. J Radiat Res. 2013; 54:899-908.

8. Mulliez T, Veldeman L, Speleers B, Mahjoubi K, Remouchamps V, Van Greveling A, Gilsoul M, Berwouts D,
Lievens Y, Van den Broecke R, De Neve W. Heart dose reduction by prone deep inspiration breath hold in left-sided breast irradiation. Radiother Oncol. 2015; 114:79-84.

9. Sung K, Lee KC, Lee SH, Ahn SH, Lee SH, Choi J. Cardiac dose reduction with breathing adapted radiotherapy using self respiration monitoring system for left-sided breast cancer. Radiat Oncol J. 2014; 32:84-94.

10. Beck RE, Kim L, Yue NJ, Haffty BG, Khan AJ, Goyal S. Treatment techniques to reduce cardiac irradiation for breast cancer patients treated with breast-conserving surgery and radiation therapy: a review. Front Oncol. 2014; 4:327.

11. Lymberis SC, deWyngaert JK, Parhar P, Chhabra AM, Fenton-Kerimian M, Chang J, Hochman T, Guth A, Roses D, Goldberg JD, Formenti SC. Prospective assessment of optimal individual position (prone versus supine) for breast radiotherapy: volumetric and dosimetric correlations in 100 patients. Int J Radiat Oncol Biol Phys. 2012; 84:902-909.

12. Chino JP, Marks LB. Prone positioning causes the heart to be displaced anteriorly within the thorax: implications for breast cancer treatment. Int J Radiat Oncol Biol Phys. 2008; 70:916-920.

13. Becker SJ, Elliston C, Dewyngaert K, Jozsef G, Brenner D, Formenti S. Breast radiotherapy in the prone position primarily reduces the maximum out-of-field measured dose to the ipsilateral lung. Med Phys. 2012; 39:2417-2423.

14. Lakosi F, Gulyban A, Janvary L, Simoni SB, Jansen N, Seidel L, Kovacs A, Vavassis P, Coucke P. Respiratory Motion, Anterior Heart Displacement and Heart Dosimetry: Comparison Between Prone (Pr) and Supine (Su) Whole Breast Irradiation. Pathol Oncol Res. 2015; 21:1051-1058.

15. Fernandez-Lizarbe E, Montero A, Polo A, Hernanz R, Moris R, Formenti S, Ramos A. Pilot study of feasibility and dosimetric comparison of prone versus supine breast radiotherapy. Clin Transl Oncol. 2013; 15:450-459.

16. Moon SY, Yoon M, Chung WK, Chung M, Shin DO, Kim DW. Comparison of Dosimetric Parameters of Patient with Large and Pendulous Breast Receiving Breast Radiotherapy in the Prone versus Supine Position. Prog Med Phys DE. 2015; 26:234-240.

17. Kirby AM, Evans PM, Donovan EM, Convery HM, Haviland JS, Yarnold JR. Prone versus supine positioning for whole and partial-breast radiotherapy: a comparison of non-target tissue dosimetry. Radiother Oncol. 2010; 96:178-184.

18. Feuvret L, Noel G, Mazeron JJ, Bey P. Conformity index: a review. Int J Radiat Oncol Biol Phys. 2006; 64:333-342.

19. Formenti SC, DeWyngaert JK, Jozsef G, Goldberg JD. Prone vs supine positioning for breast cancer radiotherapy. JAMA. 2012; 308:861-863.

20. Vaidya JS, Bulsara M, Wenz F. Ischemic heart disease after breast cancer radiotherapy. N Engl J Med. 2013; $368: 2526-2527$. 
21. Varga Z, Cserhati A, Rarosi F, Boda K, Gulyas G, Egyud Z, Kahan Z. Individualized positioning for maximum heart protection during breast irradiation. Acta Oncol. 2014; 53:58-64.

22. Offersen BV, Boersma LJ, Kirkove C, Hol S, Aznar MC, Sola AB, Kirova YM, Pignol JP, Remouchamps V, Verhoeven K, Weltens C, Arenas M, Gabrys D, et al. ESTRO consensus guideline on target volume delineation for elective radiation therapy of early stage breast cancer, version 1.1. Radiother Oncol. 2016; 118:205-208.

23. Offersen BV, Boersma LJ, Kirkove C, Hol S, Aznar MC, Biete Sola A, Kirova YM, Pignol JP, Remouchamps V,
Verhoeven K, Weltens C, Arenas M, Gabrys D, et al. ESTRO consensus guideline on target volume delineation for elective radiation therapy of early stage breast cancer. Radiother Oncol. 2015; 114:3-10.

24. Rebeis EB, Campos JR, Fernandez A, Moreira LF, Jatene FB. Anthropometric index for Pectus excavatum. Clinics (Sao Paulo). 2007; 62:599-606.

25. Gong Y, Wang J, Bai S, Jiang X, Xu F. Conventionallyfractionated image-guided intensity modulated radiotherapy (IG-IMRT): a safe and effective treatment for cancer spinal metastasis. Radiat Oncol. 2008; 3:11. 